\title{
UNIVERSIDADE POPULAR TÚLIO ESPANCA/UNIVERSIDADE DE ÉVORA: QUANDO A EDUCAÇÃO NÃO FORMAL NASCE NO SEIO DO CURRÍCULO UNIVERSITÁRIO ${ }^{1}$
}

\author{
Bravo Nico (1), Lurdes Pratas Nico (2), \\ Patrícia Ramalho (3), Ana Daniela Lopes (4)
}

(1) Universidade Popular Túlio Espanca/Universidade de Évora/ jbn@uevora.pt

(2) Universidade Popular Túlio Espanca/Universidade de Évora \& Direção de Serviços da Região Alentejo da Direção Geral de Estabelecimentos Escolares do Ministério da Educação/ Ipnico@uevora.pt

(3) Escola Comunitária de São Miguel de Machede/ SUÃO-Associação de Desenvolvimento Comunitário suao.fazerbem@gmail.com

(4) Escola Comunitária de São Miguel de Machede/ SUÃO-Associação de Desenvolvimento Comunitário suao.fazerbem@gmail.com

\begin{abstract}
Resumo
A Universidade Popular Túlio Espanca/Universidade de Évora (UPTE/UÉ) foi fundada em 2009 e, desde essa data, tem vindo a contribuir para a concretização da missão da Universidade, na dimensão da extensão/serviço à comunidade, através do desenho, construção e disponibilização de oportunidades de aprendizagem à comunidade local e regional, nas mais diversas áreas do conhecimento.

Neste texto, apresenta-se o modelo pedagógico da Universidade Popular Túlio Espanca/Universidade de Évora e salienta-se a relação mutualista que se tem vindo a tentar estabelecer entre as aprendizagens e os conhecimentos formais presentes nos planos de estudo curriculares dos estudantes da academia e as aprendizagens e os saberes experienciais presentes nos contextos educativos não formais mais frequentes no âmbito das comunidades locais da região Alentejo.
\end{abstract}

Palavras-Chave: Currículo, Ensino Superior, Educação Popular, Educação Formal, Educação não Formal

\begin{abstract}
The Popular University Túlio Espanca/University of Évora (UPTE/UÉ) was founded in 2009 and since then, has contributed to the achievement of the mission of the University, the size of the extension / service to the community through the design, construction and providing learning opportunities to local and regional community, in several areas of knowledge.
\end{abstract}

\footnotetext{
${ }^{1}$ Comunicação decorrente da concretização do projeto «Janelas Curriculares de Educação Popular no Ensino Universitário» promovido pela Universidade Popular Túlio Espanca/Universidade de Évora e financiado pela Fundação Calouste Gulbenkian, no âmbito do Programa Gulbenkian Qualificação das Novas Gerações/Projetos de Desenvolvimento do Ensino Superior/Projetos Inovadores no Domínio Educativo/ 2014
} 
In this paper, we present the pedagogical model of the Popular University Túlio Espanca/University of Évora and highlight the mutual relationship that has been trying to establish between learning and formal present knowledge in the curriculum study plans of the academy students and learning and experiential knowledge present the most frequent non-formal educational settings within local communities in Alentejo region.

Keywords: Curriculum, Higher Education, Popular Education, Formal Education, Non-formal Education

\section{A UNIVERSIDADE POPULAR TÚLIO ESPANCA (UPTE/UÉ)}

A UPTE/UÉ é uma unidade científico-pedagógica da Universidade de Évora (de acordo com o estabelecido no artigo $82 .{ }^{\circ}$ dos seus estatutos) e tem, por objetivo fundamental, garantir, aos cidadãos, oportunidades diversificadas de formação ao longo da vida, no âmbito da estratégia de entrosamento da Universidade com a sociedade envolvente.

Através da UPTE/UÉ, a Universidade de Évora pretende contribuir para a formação cultural, científica e técnica dos cidadãos da região Alentejo, através do acesso destes a modalidades de educação ao longo da vida, recorrendo, para isso, aos seus recursos científicos, culturais, físicos, tecnológicos, pedagógicos e humanos e estabelecendo parcerias com os parceiros locais, nos quais se incluem as autarquias e as organizações da sociedade civil.

De forma a garantir uma maior abrangência territorial e envolver o maior número de participantes, a UPTE/UÉ alargou a sua atividade, através do estabelecimento de parcerias na região. A UPTE/UÉ conta, atualmente, com uma rede de 5 polos, localizados em 4 concelhos alentejanos: Alandroal, Viana do Alentejo, Portel, Canaviais/Évora e São Miguel de Machede/Évora, conforme se apresenta na Figura 1:

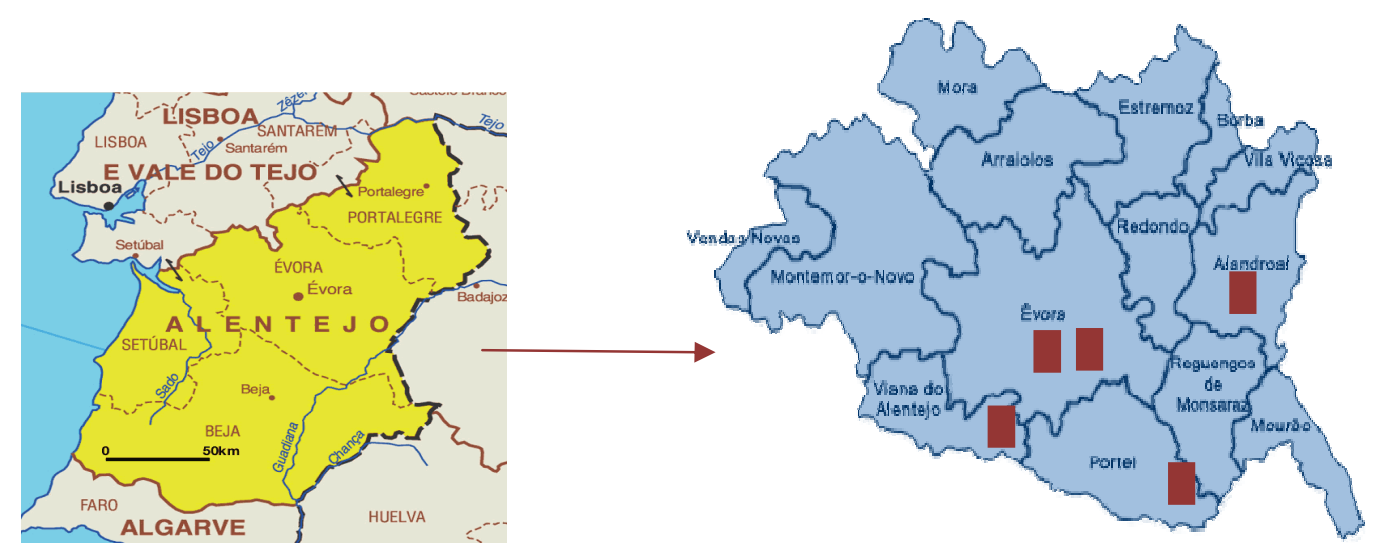

Figura 1 - Localização dos Polos da UPTE/UÉ

A rede de educação popular, entretanto constituída no território alentejano, tem vindo a promover projetos educacionais de diferentes formatos didáticos e dirigidos a públicos diversificados, de acordo com a autonomia com que cada polo prepara e concretiza as suas atividades, tendo por base uma matriz de educação popular concretizada em contextos não formais de aprendizagem e privilegiando, sempre que possível, uma abordagem intergeracional.

A geografia territorial e institucional das parcerias não se circunscreveu à cidade de Évora, sendo que, desde o início, se assumiu o próprio território alentejano como um contexto formador [Nico, (2013), Nico, B. \& Nico. L. (2011)] e, consequentemente, como um, importante e rico, recurso curricular (Nico \& D'Orey, 2004). 


\section{A PEDAGOGIA DA UNIVERSIDADE POPULAR TÚLIO ESPANCA (UPTE/UÉ)}

As atividades de aprendizagem, na UPTE/UÉ, têm vindo a ser desenhadas e concretizadas considerando, sempre que possível, as histórias de vida dos participantes, nas suas dimensões social, académica profissional e pessoal. Ao assumir essa dimensão biográfica dos projetos educativos desenvolvidos, a UPTE/UÉ pretende contribuir para a valorização de todo o percurso vital de cada indivíduo, qualquer que seja a sua circunstância académica, o seu contexto pessoal ou profissional ou as suas motivações para a participação nos projetos educativos, uma vez que a aprendizagem é um comportamento humano que não conhece fronteiras, de espaço ou de tempo e "os conhecimentos que acumulámos, as capacidades e competências que edificámos ou as atitudes que desenvolvemos são o resultado da totalidade dos episódios de aprendizagem que, ao longo da vida e em todas as dimensões, vamos concretizando" (Nico, 2006:197).

A UPTE/UÉ privilegiou a educação não formal, como contexto de aprendizagem, atendendo, entre outros, aos seguintes aspetos:

(i) A educação não formal é assumida como uma vertente fundamental de uma educação permanente e pode ocorrer em diferentes espaços formativos, sendo entendida por Santos e Fidalgo (2007:79), como um "processo educacional organizado e sistematizado que ocorre fora da instituição formal de ensino e que tem como objetivo o desenvolvimento humano (...)". Por outro lado, os contextos de educação não formal encontram-se presentes em todas as comunidades locais e são bastante participados por uma população com baixos índices de escolarização e taxas razoáveis de participação na vida das instituições locais;

(ii) A educação não formal refere-se a atividades educativas que são, por vezes, estruturadas para responder a algumas necessidades e lacunas do sistema educativo tradicional (formal),sendo que, na definição dos seus objetivos, há que ter em conta "as características dos educandos/formandos, bem como das características do contexto local específico" (Nogueira, 1996:...);

(iii) As aprendizagens que se concretizam em contextos não formais, apesar de não conferirem uma certificação, de nível escolar ou profissional, proporcionam a aquisição de competências diversificadas e importantes para o exercício da cidadania, como nos refere Trigo (2001:102; 2002:19);

(iv) Os contextos não formais de aprendizagem possibilitam o 'encontro' de todos os saberes, todas as didáticas, todas as pessoas, todas as gerações e todas as motivações. Este 'encontro de todos com tudo'é um dos pilares do modelo pedagógico da UPTE/UÉ;

(v) Os pressupostos que estão na base das atividades de educação formal e popular desenvolvidas na UPTE/UÉ decorrem, ainda, das recomendações das instituições internacionais mais relevantes na área, como são a UNESCO e a Comissão Europeia (CE). Em 2000, a CE foi responsável pelo Memorando sobre a Aprendizagem ao Longo da Vida, no qual se afirmava a importância da aprendizagem na vida das pessoas através da disponibilização de:

"Oportunidades diversificadas de aprendizagem ao longo da vida
acessíveis a nível local contribuem para que as pessoas não se
sintam obrigadas a abandonar a sua região de origem para fins de
educação e formação - ainda que deva ser-lhes dada a oportunidade
de o fazer e velar por que essa mobilidade seja uma experiência de
aprendizagem positiva. Para alguns grupos, como as pessoas com
deficiência, nem sempre é possível uma mobilidade física. Nestes
casos, a igualdade de acesso à aprendizagem só poderá ser
concretizada aproximando a mesma dos próprios aprendentes."
(Comissão das Comunidades Europeias, 2000: 22)

A UPTE/UÉ é, assim, uma escola para todos e para a vida toda, na qual se pretende concretizar o princípio de ensinar tudo a todos, de todas as maneiras possíveis, preconizado por Coménio, na conhecida obra Didática Magna, publicada no longínquo ano de 1649, pouco mais de um século antes da fundação da Universidade de Évora (1559). 
Desde a sua fundação, a UPTE/UÉ tem promovido projetos educacionais, em contexto não formal, de matriz popular e dirigidos a públicos pouco escolarizados e mais distantes, geográfica e socialmente, dos percursos e das rotinas de qualificação formal. No âmbito destes projetos, têm participado professores e estudantes das diferentes áreas científicas e de formação da Universidade de Évora, que, de forma voluntária, se têm empenhado na promoção de variadas atividades de divulgação cultural e científica.

No que respeita, em concreto, aos dispositivos didáticos que têm concretizado a missão da UPTE/UÉ, destacam-se os seguintes:

1. Cursos Breves: oportunidades de formação de curta duração concebidas e concretizadas, de acordo com interesses e necessidades individuais ou institucionais e adaptadas aos recursos existentes, em cada momento, na Universidade de Évora e nas instituições parceiras, caso existam.

2. Ações Singulares: oportunidades de aprendizagem de cariz pontual, que assumem vários formatos (Palestras, Conferências, Seminários, Mesas-Redondas, etc.).

3. Visitas De Estudo: oportunidades de aprendizagem que pressupõem a deslocação dos participantes a um determinado local. As visitas de estudo poderão ocorrer dentro da própria Universidade de Évora ou no seu exterior.

4. Janelas Curriculares de Educação Popular: episódios de educação popular de perfil não formal e intergeracional desenhados e concretizados no seio dos planos de estudo curriculares disponibilizados pela Universidade de Évora, no âmbito da sua oferta formativa regular. Estas atividades são previamente negociadas e definidas pelos docentes e discentes, nas unidades curriculares em que as mesmas ocorrem, e oportunamente divulgadas, no âmbito do projeto educativo da Universidade Popular Túlio Espanca, para cada ano letivo;

5. Outros Formatos: dispositivos de formação com geometria funcional e temporal diversificada, sempre que as circunstâncias o aconselhem e as condições o permitam. (cf. www.utulioespanca.uevora.pt).

\subsection{As Janelas Curriculares de Educação Popular na Universidade de Évora}

Nos últimos dois anos, a UPTE/UÉ desenvolveu um projeto inovador no ensino superior português denominado "Janelas Curriculares de Educação Popular no Ensino Superior Universitário", financiado pela Fundação Calouste Gulbenkian, no âmbito do Concurso de Projetos Inovadores no Domínio Educativo /Desenvolvimento do Ensino Superior/Programa Gulbenkian Qualificação das Novas Gerações 2014.

O projeto concretizou-se entre 1 de Setembro de 2014 e 31 de Agosto de 2016 e, desde o seu início, foi assumido como:

i) um recurso didático disponível na Universidade de Évora, para a valorização das aprendizagens dos estudantes;

ii) um instrumento privilegiado para a socialização do conhecimento científico e cultural produzido e ensinado na academia;

iii) uma oportunidade única de diálogo entre os sabres académicos e os conhecimentos experienciais.

Através deste projeto, a academia iniciou um processo de integração da educação popular no contexto curricular dos planos de estudo de alguns estudantes, com a supervisão dos respetivos docentes.

O objetivo geral do projeto consiste em proporcionar, aos estudantes da Universidade de Évora, oportunidades de conceber, planificar e concretizar projetos de educação não formal abertos à participação da população do Alentejo, decorrentes da mobilização e valorização do conhecimento e das competências científica, cultural, técnica e tecnológica presentes na respetiva formação académica e enquadrados, sempre que possível, no âmbito dos planeamentos didáticos das unidades curriculares frequentadas.

O projeto assenta no pressuposto de que, em contexto curricular, é possível e qualitativamente vantajoso para a qualidade das aprendizagens, a substituição de alguns 
instrumentos didáticos e de avaliação pela participação discente em projetos de divulgação e promoção científicas, nos quais se mobilizam e aplicam, em contexto de educação popular, os conhecimentos e as competências edificados na academia. Por outro lado, a certificação dessa participação, em complementaridade com a certificação académica tradicional, diferenciará o curriculum vitae dos estudantes participantes, porque o enriquece com competências habitualmente ausentes dos currículos académicos, mas valorizadas em futuros contextos profissionais.

A organização do projeto teve como base as ideias em torno da definição de currículo preconizadas por Sacristán (1995). Segundo este autor, o currículo deve ser "entendido como um projeto ou plano educativo composto de distintos aspetos, experiências, conteúdos, etc.; (...) percecionado através da sua função social, em torno da qual também se estrutura a ligação entre a sociedade e os sistemas educativos". Neste contorno conceptual, o projeto pretende proporcionar, aos estudantes da Universidade de Évora - através da sua participação na atividade institucional da Universidade Popular Túlio Espanca (UPTE/UÉ) -, oportunidades de conceber, planificar e concretizar projetos de educação não formal abertos à participação da população do Alentejo, mobilizando o seu portefólio de conhecimentos e competências, oriundos da respetiva formação académica, e supervisionados pelos seus professores, sempre que possível.

A concretização deste projeto na academia eborense conduziu à instituição de um novo conceito - 'janela curricular' (Nico et al, 2015a; Nico et al, 2015b). Esta é entendida como um segmento do processo de aprendizagem e de avaliação dos estudantes nas unidades curriculares que estes frequentam, no âmbito do respetivo curso/plano de estudos. Uma das componentes deste processo de aprendizagem e de avaliação pode consistir (conforme exemplo que descreveremos adiante) num trabalho de natureza mais prática, que complementa e enriquece os processos mais clássicos de aprendizagem e de avaliação, uma vez que os estudantes evidenciam, na realidade concreta, os conhecimentos e as competências adquiridas e, dessa forma, proporcionam oportunidades de aprendizagem à comunidade regional, nomeadamente aos estudantes da UPTE/UÉ pertencentes à sua rede de polos.

Através destas janelas curriculares, os estudantes não só demonstram possuir os conhecimentos e as competências académicas, como têm oportunidade de desenvolver outras competências, hoje, muito valorizadas no mercado de trabalho (liderança, comunicação, responsabilidade, autonomia, trabalho em equipa, resolução de problemas, contacto com outras línguas, etc.) e, também, competências de grande valor humano e axiológico, como a solidariedade, o respeito pelos conhecimentos não académicos (experiencial) e a cooperação intergeracional.

Em síntese, podemos afirmar que uma janela curricular é uma oportunidade mais humanizada de concretizar a formação universitária, conferindo utilidade social ao conhecimento académico.

Apresentamos um exemplo de uma janela curricular concretizada no ano letivo 2015/2016 (Visita de Estudo a Campo Maior), descrevendo os passos mais significativos da sua preparação e consequente concretização:

(i) Num primeiro momento, os estudantes da unidade curricular Projetos de Intervenção em Educação procederam a um levantamento de algumas histórias de vida da população residente no Bairro de Almeirim/Évora. Desse trabalho, desenvolvido de recolha biográfica, resultaram algumas pistas de projetos a desenvolver, atendendo a episódios significativos identificados em algumas biografias, nos quais o denominador comum era Campo Maior;

(ii) A janela curricular compreendeu a realização de duas sessões de preparação da visita de estudo a Campo Maior, nas quais participaram docentes e discentes voluntários de diversos domínios científicos da Universidade de Évora. Verificaram-se, também, os contributos da Associação de Moradores do Bairro de Almeirim, da Escola Comunitária de São Miguel de Machede e da Junta de Freguesia dos Canaviais. Este projeto, além de contar com a participação de estudantes e docentes do Curso de Licenciatura em Ciências da Educação, envolveu estudantes e docentes de outras áreas científicas que 
ficaram responsáveis pela abordagem de diferentes aspetos de Campo Maior (Arquitetura, Química, Biologia, História, Arqueologia, Sociologia, Agronomia, etc.);

(iii) Antes da realização da visita de estudo, ocorreu uma sessão de apresentação e de enquadramento prévio da visita e estudo, nas instalações da Associação de Moradores do Bairro de Almeirim. Nesta sessão, foi apresentado o roteiro da visita e os alunos e docentes envolvidos deram contributos para a sua organização, nas respetivas áreas científicas, conforme referido no ponto anterior;

(iv) Em 14 de Junho de 2015, ocorreu a Visita de Estudo a Campo Maior, que envolveu a participação de pessoas dos Bairros de Almeirim e dos Canaviais, da vila de São Miguel de Machede e de estudantes, docentes e investigadores da Universidade de Évora;

(v) A realização desta visita permitiu valorizar o conhecimento académico (conhecimentos de docentes e discentes aplicados à história de Campo Maior, à sua indústria agroalimentar do café e do azeite ou à sua cultura popular presente nas conhecidas Festas do Povo) e o conhecimento experiencial (conhecimento empírico associado às ervas aromáticas e às suas aplicações no quotidiano, à ingestão quotidiana do café ou às visitas realizadas às festividades populares);

(vi) A visita de estudo promoveu a intergeracionalidade, a partilha de saberes, a confraternização, a aquisição de novos conhecimentos e competências para todos os envolvidos e, dessa forma, constituiu-se como um grande 'encontro' de todos os saberes, todas as pessoas, todas as gerações e todas as didáticas.

\section{CONCLUSÃO}

A participação de investigadores, docentes, estudantes e funcionários da Universidade de Évora e de pessoas com outras origens institucionais, diferentes ocupações profissionais e diversos níveis de escolaridade, nas atividades educativas da UPTE/UÉ, tem vindo a proporcionar uma oportunidade de aproximação entre os contextos formal e não formal de aprendizagem e as respetivas didáticas, num encontro educativo e inclusivo de saberes, pessoas e didáticas. Esta interação entre a academia e a região tem proporcionado vantagens recíprocas:

i) Aos estudantes da Universidade de Évora, é dada a oportunidade de concretizarem, em contexto real, projetos de educação popular que convocam, valorizam e materializam os seus conhecimentos e competências e que lhes proporcionam a oportunidade de adquirirem saberes e capacidades ausentes dos planos curriculares das suas formações académicas;

ii) Aos estudantes da UPTE/UÉ, é dada a oportunidade de acederem a atividades de educação popular desenhadas e concretizadas por estudantes e professores da academia e com conteúdos normalmente ausentes dos seus quotidianos. Por outro lado, os seus saberes, de matriz mais experiencial, são valorizados e partilhados, em plano de igual valor e dignidade, com os conhecimentos mais académicos.

Nos últimos dois anos, a UPTE/UÉ viu reconhecido o seu trabalho, através da aprovação e financiamento de dois projetos seus, pela Fundação Calouste Gulbenkian, no âmbito do Programa Gulbenkian Qualificação das Novas Gerações/Projetos de Desenvolvimento do Ensino Superior.

\section{Referências Bibliográficas}

Comissão das Comunidades Europeias (2000). Documento de Trabalho dos Serviços da Comissão das Comunidades Europeias Memorando sobre Aprendizagem ao Longo da Vida. Recuperado de https://infoeuropa.eurocid.pt/files/database/000033001000034000/000033814.pdf

D’Orey, J. \& Nico, B. (2004). Gestão curricular local: fundamento para a promoção da literacia científica. in Bravo Nico et al. Aprender no Alentejo - II Encontro Regional de Educação. Évora: Departamento de Pedagogia e Educação da Universidade de Évora. pp. 111-115. 
Nico, B. (2006). Práticas Educativas e Aprendizagens Formais e Informais: encontros entre cidade, escola e formação de Professores. in Inês Bragança et al (Orgs.) Vozes da Educação: Memórias, histórias e formação de professores. Petrópolis: DP et Alii Editora Ltda. pp. 197-206.

Nico, B. (2013). Passado e Futuro no Presente dos Percursos de Qualificação: A Equação da Aprendizagem. in Elisa Chaleta et al (Orgs). Atas da II International Conference Learning and Teaching in Higher Education/ Learning Orchestration in Higher Education. Évora: Universidade de Évora. pp. 312-317.

Nico, L. (2009). Avaliação do(s) Impacto(s) do Processo de Reconhecimento, Validação e Certificação de Competências (RVCC), no Alentejo (período 2001-2005) [Tese apresentada à Universidade de Évora, tendo em vista a obtenção do Grau de Doutor em Ciências da Educação]. Évora: Universidade de Évora (policopiada).

Nico, B. \& Nico, L. (Orgs.) (2011). Qualificação de Adultos: realidades e desafios no Sul de Portugal. Mangualde: Edições Pedago.

Nico, B., Nico, L., Tobias, A., Barnabé, J. (2015a). Universidade Popular Túlio Espanca (UPTE): o encontro entre a Universidade de Évora, a Educação não Formal e o Alentejo. Revista de Estudios e Investigación en Psicología Y Educación, vol. Extra, (5) 29-32.

Nico, B., Nico, L., Tobias, A., Barnabé, J., Ramalho, P. \& Lopes, D. (2015b). Janelas Curriculares de Educação Popular na Universidade de Évora: dar utilidade social ao conhecimento académico. Revista de Estudios e Investigación en Psicología Y Educación, vol. Extra, (5) pp. 33-37.

Nogueira, (1996). Para uma Educação Permanente à Roda da Vida. Coimbra: Instituto de Inovação Educacional.

Sacristán, J. (1995). El curriculum: una reflexion sobre la pratica. Madrid: Ed. Morata

Santos, N. \& Fidalgo, F. (2007). Os (des)caminhos da certificação de competências no Brasil. in Fernando Fidalgo et al (Orgs.). Educação Profissional e a Lógica das Competências. Petrópolis: Editora Vozes. pp. 71-110.

Trigo, M. (2001). O presente e o futuro da educação de adultos em Portugal. in Revista Portuguesa de Pedagogia. Ano 35. (1). Coimbra: Faculdade de Psicologia e de Ciências da Educação. pp. 101-114.

Trigo, M. (2002). Importância das aprendizagens não formais e informais na formação dos adultos. in Revista Saber Mais. 12. Lisboa: ANEFA. pp. 18-20. 